\title{
PENERAPAN METODE NARASI ARSITEKTUR DALAM PERANCANGAN EKSTRAKURIKULER PENDIDIKAN EKOLOGI DI KAWASAN EDUTOWN, BSD
}

\author{
Ferdi James $^{1)}$, Fermanto Lianto ${ }^{2)}$ \\ 1)Program Studi S1 Arsitektur, Fakultas Teknik, Universitas Tarumanagara, jamesferdi1@gmail.com \\ 2) Program Studi S1 Arsitektur, Fakultas Teknik, Universitas Tarumanagara, fermantol@untar.ac.id
}

\begin{abstract}
Abstrak
Kehidupan di perkotaan yang selalu mengalami percepatan dan cenderung kapitalis membuat manusianya kurang peka terhadap lingkungannya. Pendidikan di perkotaan, siswa hanya belajar tentang alam dan lingkungan melalui literasi dan kurang kesempatan belajar langsung dari alam di perkotaan. Hal ini yang berdampak akan kurangnya kesadaran dan pola pikir serta perilaku tak acuh terhadap alam dan lingkungan sekitarnya. BSD City dengan segala percepatan kemajuan dan perkembangannya harus diimbangi pula dengan pola perilaku masyarakat yang sadar dan peduli akan lingkungan. Proyek ini merupakan langkah tindakan preventif terhadap kerusakan lingkungan. Teknologi dan material harus sustainable dan ramah lingkungan, namun yang fundamental adalah perilaku manusia yang harus sustainable dan ramah pula terhadap lingkungan dan alam. Oleh karena itu melalui program "Ekstrakurikuler Pendidikan Ekologi di Kawasan Edutown, BSD", dengan menggunakan metode narasi dengan pendekatan ekologi budaya untuk membantu dalam penanganan pola pikir dan perilaku manusia terhadap alam dan lingkungan. Diharapkan melalui proyek ini kesadaran, pola pikir dan perilaku siswa-siswa terhadap alam dan lingkunganya dapat berubah, sehingga tercipta generasi penerus bangsa yang tidak hanya cerdas secara intelektual, namun juga akhlak kepada Tuhan, sesama dan lingkungan. Sehingga kedepannya manusia dapat berjalan berdampingan dengan alam dan menjaga keberlangsungannya.
\end{abstract}

Kata kunci: ekologi; pendidikan; lingkungan; ekstrakurikuler; narasi arsitektur

\begin{abstract}
Life in urban areas, which is accelerating and capitalist, makes humans less sensitive to their environment. Students only learn about nature and the environment through literacy and lack opportunities to learn directly from nature in urban areas. It causes a lack of awareness and mindset and indifferent behaviour towards nature and the surrounding environment within the city. With all the acceleration of development, BSD City must be balanced with the behavioural pattern of people who are aware and care about the environment. This project is a preventive measure against environmental damage. Technology and materials must be sustainable and environmentally friendly, but what is fundamental is human behaviour that must be sustainable and friendly to the environment and nature. Therefore, through the program "Ecological Education Extracurricular in the 'Edutown' Area, BSD," using the narrative method with a cultural ecology approach to assist in handling human thought patterns and behaviour towards nature and the environment. Through this project, it is hoped that students' awareness, mindset, and behaviour towards nature and its environment can be changed, developing the next generation of the nation who is intellectually intelligent and morally towards God, others, and the environment. Therefore in the future, humans can walk side by side with nature and maintain its sustainability.
\end{abstract}

Keywords: ecology; education; environment; extracurricular; narrative architecture 


\section{PENDAHULUAN}

Dewasa ini, pembicaraan tentang perusakan lingkungan tengah menjadi bahan sorotan di seluruh dunia. Lingkungan hidup merupakan suatu kesatuan ruang dengan segala organisme yang ada di dalamnya termasuk benda, kondisi serta makhluk hidup yang mencakup manusia serta perilakunya yang berdampak pada kelangsungan dan kesejahteraan makhluk hidup yang ada di dalamnya. Perubahan kondisi alam secara besar-besaran akan menimbulkan pengaruh kepada keseimbangan ekosistem dan memiliki peluang untuk merusak ekosistem yang pada akhirnya berdampak pada kematian organisme yang ada di dalamnya. Kesadaran masyarakat yang rendah dalam memelihara lingkungan tentunya akan berpengaruh terhadap kesehatannya. Permasalahan umum yang kerap terjadi di perkotaan yaitu meliputi perilaku konsumtif, membuang sampah sembarangan, pembakaran sampah, pengambilan air tanah secara berlebihan. Tindakan tersebut tentunya berpenharuh buruk terhadap lingkungan. Akibat dari rendahnya kesadaran masyarakat akan lingkungan dan perilakunya yang sudah membudaya sehingga banyak masalah bermunculan dan dianggap hal yang lumrah.

Salah satu penyebab kurangnya kesadaran masyarakat akan lingkungan yaitu dari pendidikan akan lingkungan yang diajarkan sejak dari dini dinilai kurang ditekankan. Pendidikan kita khususnya di perkotaan menggunakan penekanan pada media pembelajaran buku, media elektronik, dan peningkatan waktu menjadi hal yang lebih lazim. Sehingga terjadi pemutusan hubungan antara anakanak dengan alam (Zepke \& Leach, 2010). Literasi tentang alam menjadi lebih sulit. Hal ini terjadi bukan karena kurangnya buku tentang alam, tetapi berkurangnya kesempatan untuk mengalami alam dengan langsung (Orr, 1992). Hubungan dan pengalaman di alam dapat membentuk konsepsi dan mendorong anak-anak untuk sadar akan lingkungan (Zepke \& Leach, 2010). Oleh karena itu dalam rangka meningkatkan kepedulian dan menciptakan pola pikir baru terhadap alam sebagai tindakan preventif terhadap perusakan lingkungan dan menciptakan kondisi pembelajaran yang sehat dan menyenangkan, diperlukan suatu desain arsitektur dengan menggunakan metode Narrative Architecture dan pendekatan ekologi budaya. Narasi digunakan untuk menyatukan pemahaman antara arsitek, pendidik, dan anak-anak, dimana anak-anak dapat tergugah pikiran dan perasaannya terhadap lingkungan sehingga memberikan pengaruh terhadap pola pikir siswa terhadap alam nantinya, dimana para siswa dapat bukan hanya mempelajari tetapi mengenal dan menghargai alam tepat di depannya. Diharapkan nantinya dapat menghasilkan generasi penerus bangsa yang peduli terhadap lingkungan.

\section{KAJIAN LITERATUR}

\section{Ekologi}

\section{Pengertian Ekologi}

Ekologi merupakan ilmu yang mempelajari hubungan antara organisme dengan lingkungannya. Ekologi memiliki akar kata dari bahasa Yunani yaitu oikos (" habitat") dan logos ("ilmu"). Ernst Haeckel (18341914) merupakan orang yang pertama kali mengemukakan terminologi dari ekologi. Ilmu ekologi mempelajari makhluk hidup sebagai kesatuan atau sistem yang berinteraksi dengan sesamanya dan dengan lingkungannya (Dosen Pendidikan 2, 2020).

\section{Prinsip-Prinsip dari Ekologi}

Berikut adalah prinsip-prinsip ekologi yakni (Bella, 2020):

- Interaksi (Interaction)

Relasi antara individu yang satu dengan individu yang lainnya dalam suatu populasi yang satu atau yang lainnya.

- Saling ketergantungan (Interdependence)

Di dalam suatu ekosistem, hewan, tumbuhan, manusia, serta makhluk hidup lainya terjalin sebuah relasi yang memiliki sifat ketergantungan untuk dapat hidup.

- Keanekaragaman (Diversity) 
Merupakan relasi antara manusia dengan alam, beserta tumbuhan dan hewan yang ada di dalamnya.

- Keharmonisan (Harmony)

Hubungan antara manusia dengan alam lingkungan yang terjalin secara baik.

- Kemampuan untuk berkelanjutan (Sustainability)

Adalah sebuah sistem di alam dimana secara mandiri menghidupi keanekaragaman hayati di dalamnya serta berlangsung secara berkelanjutan.

\section{Sekolah Alam}

\section{Alam dalam arti pengalaman}

Sekolah alam memiliki pendekatan dimana siswa diarahkan untuk melewati sebuah rangkaian kegiatan yaitu melalui pengalaman serta pengamalan, lalu distrukturkan. Berbeda halnya dengan pendidikan secara umum yang ada di Indonesia, berbanding terbalik di mana buku pelajaran dipelajari dulu oleh siswa, lalu setelahnya baru diamalkan (Suhendi \& Murdiana, 2011).

\section{Alam dalam arti semesta alam}

Hukum dan konsep alam semesta yaitu tunduk di bawah kuasa Tuhan Yang Maha Esa. Salah satunya yaitu fenomena gravitasi, dimana pusat bumi merupakan pusat arah benda-benda yang jatuh. Ketergantungan makhluk hidup akan perlunya sinar matahari. Daur hidup karbon, nitrogen, air, serta oksigen yang berguna di dalam kehidupan. Siklus tersebut terjadi atas kendali dan kehendak Tuhan Yang Maha Esa (Suhendi \& Murdiana, 2011).

Kita diajarkan oleh alam untuk menjadi pribadi yang memiliki ketangguhan. Semua kejadian yang terjadi di alam memberikan kita hikmat serta pengetahuan yang menjadi dasar dari terbentuknya ilmu pengetahuan. Kita yang mau berpikir serta belajar dari alam dapat memiliki ilmu pengetahuan tersebut (Suhendi \& Murdiana, 2011).

\section{Metode Pembelajaran}

Belajar Bersama Alam (BBA) merupakan metode pembelajaran yang digunakan, dimana sarana utama dalam kegiatan belajar mengajar memanfaatkan potensi sumber daya lingkungan yang ada. Di dalam proses kegiatan belajar mengajar, kegiatan belajar dari pengalaman adalah aktivitas utamanya. Pendidik harus memiliki sifat suka untuk bereksperimen. Pola pembelajaran adalah 70:30 dimana 30\% berada di dalam kelas, sedangkan 70\% nya berada di luar kelas (Suhendi \& Murdiana, 2011).

\section{Narrative Architecture}

Narasi berasal dari Bahasa latin yaitu narratio, yang memiliki arti yaitu cerita. Terdapat dua aspek dalam hubungan antara cerita dan narasi yaitu cerita itu sendiri, konten, komunikasi, serta ekspresi bagaimana cerita tersebut dibawakan. Narasi merupakan sebuah multi interaksi, hal ini memiliki kesamaan sebagaimana arsitek dan pengguna di dalamnya diperlukan di dalam arsitektur. Di sinilah di mana titik dimana arsitektur dan narasi bergabung. Di dalam setiap ruang spasial, arsitek memberikan bentuk berupa konteks yang memiliki perbedaan (Psarra, 2009).

Ciri-ciri dari arsitektur naratif adalah sebagai berikut (Tissink, 2016):

a) Linking/hubungan

Menghubungkan lingkungan dan identitas. Seseorang dapat merasakan hubungan terhadap lingkungan yang menciptakan sebuah identitas melalui narasi, cerita, kejadian dan memori.

b) Structuring/Kerangka

Salah satu peran arsitektur naratif yaitu memberikan kerangka cerita ke dalam pengalaman spasial. Dengan diberikannya kerangka narasi, maka kebutuhan akan ruang spasial, program, serta gubahan massa dari suatu bangunan yang disesuaikan dengan proses serta pengalaman spasial berdasarkan pada alur cerita yang dibuat dapat ditentukan oleh arsitek. 


\section{c) Framing/Pembingkaian}

Salah satu upaya arsitektur naratif yaitu pembingkaian yang bertujuan untuk memanipulasi pandangan dan pemikiran seseorang. Pembingkaian mengarahkan orang menuju suatu perspektif tertentu, melewati alur yang telah dirancang, dan dibuat tertarik oleh suatu elemen tertentu yang telah dirancang arsitek.

\section{Playscape}

Playscape merupakan area bermain yang sengaja di desain dengan tujuan untuk menghubungkan anak-anak dengan bagian-bagian alam seperti pohon, air, tanah, dan elemen lainnya (Luken, Carr, \& Brown, 2014).

Dengan ketidakhadiran lansekap alam seperti area ruang terbuka, perhutanan, dan ruang terbuka hijau lainnya di perkotaan, playscape alami memberikan peluang kepada anak-anak untuk terhubung dengan alam. Permainan alam merupakan pengalaman bermain di mana anak-anak mengeksplorasi dan berinteraksi dengan bahan-bahan yang terjadi di lingkungan alam.

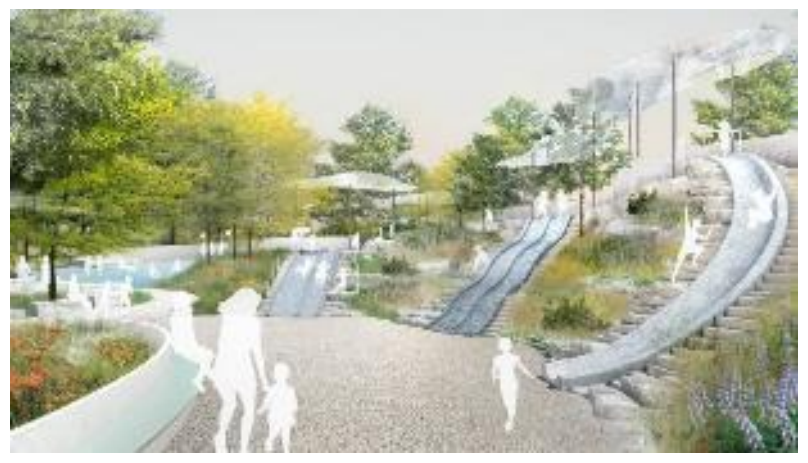

Gambar 1. Ilustrasi Playscape

Sumber: https://bkskarch.com/2020/03/26/battery-playscape-receives-asla-ny-design-award/ diakses 2 Juli 2021

Selain bermain dan bereksplorasi, ruang terbuka juga menyajikan ruang lain yang penting untuk kebutuhan perkembangan, yaitu: aktivitas fisik dan kesehatan. Penelitian telah mendokumentasikan potensi risiko membatasi waktu anak di ruang luar ruangan yaitu kesulitan untuk memperhatikan, terbatasnya persepsi sensorik, dan tingkat fisik dan emosional yang lebih tinggi (Kuh, Ponte, \& Chau, 2013).

\section{METODE}

Dalam merancang sebuah objek arsitektur secara efektif, dibutuhkan sebuah pendekatan sebagai suatu metode untuk menganalisis dan merancang. Pendekatan dapat diaplikasikan untuk mengatur program ruang, visualisasi ruang, konstruksi, pengalaman ruang, serta tatanan ruang. Ada banyak macam pendekatan arsitektur yang dapat diaplikasikan. Agar dapat membantu dalam proses merancang, pemilihan dari pendekatan tergantung kepada objek yang akan dirancang serta metode yang digunakan oleh perancang.

Dalam Peta Metode Desain terdapat empat metode dalam arsitektur yaitu: Metode dalam dunia seni, sains, perilaku dan environmental (lingkungan). Metode dalam dunia seni yaitu yaitu sebuah wilayah metode yang dibangun berdasarkan subyektifitas perasaan (mengandalkan nilai estetika-intuisi). Salah satu metodenya yaitu narasi yang dikembangkan berdasarkan nilai intuisi, sensasi (perasaan), kreatifitas dan romantisme.

Narasi sebagai sebuah metode menjembatani ruang dalam alur bahasa cerita, setiap teks yang dikeluarkan menjadi wacana keruangan yang terbuka dan menjadi tempat untuk berinterpretasi 
(Sutanto, 2020). Metode yang digunakan yaitu menggunakan metode narasi dengan berdasarkan pada "Ekologi Budaya" menurut Julian Haynes Steward dimana ekologi budaya merupakan cara pandang memahami persoalan lingkungan hidup dalam perspektif budaya, dan sebaliknya. Keduanya tidak bisa dilihat terpisah dan memiliki sifat unik yang saling mempengaruhi (Susilo, 2008). Kehidupan manusia tidak dapat terlepas dari alam dan selalu bergantung kepadanya, tetapi pada waktu yang bersamaan perubahan lingkungan dipengaruhi oleh perilaku manusia. Sifat alam yang terlihat tidak bersahabat kepada kita tidak terlepas dari perilaku manusia yang berbuat semaunya terhadap lingkungan, namun di sisi lain manusia diberikan Tuhan Yang Maha Esa kemampuan untuk menyadari dampak yang menakutkan dari alam, lalu manusia memikirkan langkah kedepannya yang terbaik untuk menyelamatkan dan memberdayakan alam itu, sehingga keduanya dapat menemukan titik keseimbangan (Susilo, 2008).

Dalam perancangan ini metode narasi yang digunakan dibagi menjadi empat tahapan pembelajaran dalam narasi ekologi yaitu sebagai berikut:

- Pembelajaran Tahap Pertama

Anak-anak diberi pengenalan dan diajarkan tentang dasar-dasar ekologi, fenomena-fenomena alam yang ada, bagaimana ekosistem bekerja

- Pembelajaran Tahap Kedua

Anak-anak diberi pengalaman tentang kerusakan ekologi seperti mencairnya es, penebangan hutan, peningkatan suhu dan dampaknya terhadap kehidupan

- Pembelajaran Tahap Ketiga

Anak-anak diajarkan untuk memperbaiki ekologi dengan menanam pohon, cara hidup yang berkelanjutan dengan energi-energi terbarukan melalui eksperimen dan demonstrasi

- Pembelajaran Tahap Keempat

Anak-anak diajarkan untuk memelihara lingkungan, manfaat-manfaat dari pohon. Kehidupan dan biodiversitas yang terjadi di antara pepohonan. Serta adanya program camping outdoor untuk merasakan pengalaman yang lebih jauh.

Selain itu digunakan juga teori elemen pembentuk kota karya Kevin Lynch dalam bukunya "The Image of The City" untuk diterapkan di dalam tapak perancangan tersebut berupa (Lynch, 1960):

- Path

Path merupakan jalur dimana seseorang biasanya bergerak, berjalan dan melewatinya serta merupakan sirkulasi yang biasanya dilalui seseorang untuk berpindah dari suatu titik ke titik lainnya.

- Edges

Edges bukan merupakan sirkulasi untuk pengamat, namun merupakan elemen pembatas yang bersifat linear. Elemen ini berfungsi untuk memberikan suatu batasan dalam suatu area untuk menjaga keamanan dan privasi.

- District

District adalah kawasan yang bersifat dua dimensi yang berskala menengah hingga luas, dimana manusia dapat merasakan batasan masuk dan keluar dari wilayah yang memiliki sifat dan karakter yang berbeda dan setiap wilayah memiliki ciri dan kesamaan tertentu.

\section{- Nodes}

Nodes merupakan titik dan spot yang strategis dimana seseorang dapat masuk, dan yang merupakan titik pusat untuk menentukan ke arah mana ia mau bergerak. Nodes dapat berupa persimpangan jalan, tempat singgah untuk berhenti sejenak dari jalur, persimpangan dari path, dan dapat berupa ruang terbuka.

- Landmark

Landmark merupakan titik acuan seperti elemen nodes, hanya saja tidak masuk ke dalamnya karena landmark ini merupakan elemen eksternal yang dapat terlihat dari luar dan memiliki visual yang menarik ataupun mencolok. 


\section{DATA TAPAK}

Tapak berada di Jl. Edutown, Pagedangan, Kecamatan Pagedangan, Kab.Tangerang Luas Tapak $=15.000 \mathrm{~m} 2$

$\mathrm{KDB}=40 \% 6.000 \mathrm{~m} 2$

$\mathrm{KDH}=60 \% 9.000 \mathrm{~m} 2$

Batas Utara $=\mathrm{Jl}$. Edutown (Edutown Arena)

Batas Barat $=$ Sekolah Tinggi Agama Buddha

Negeri Sriwijaya

Batas Timur $=$ SGU University

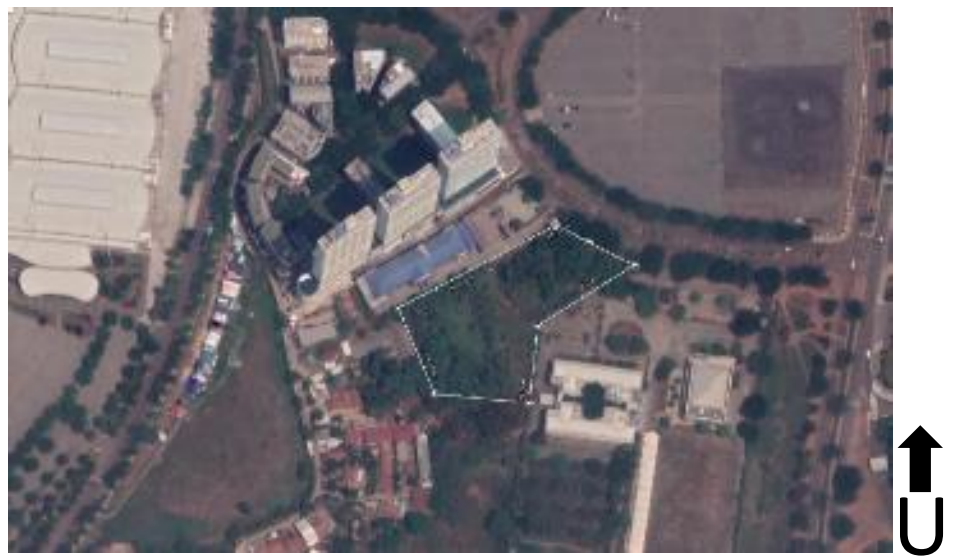

Gambar 2. Tapak Terpilih

sumber: googlemaps.com diakses 2 Juli 2021

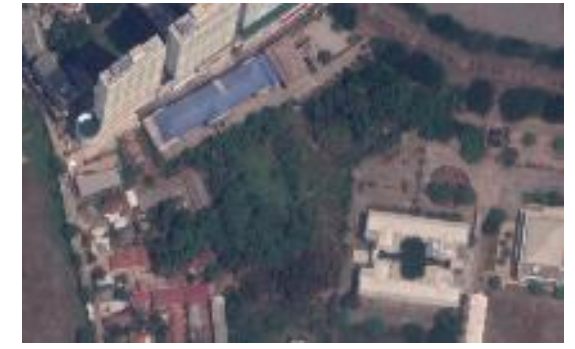

Gambar 3. Bird eye view tapak eksisting sumber: googlemaps.com diakses 2 Juli 2021

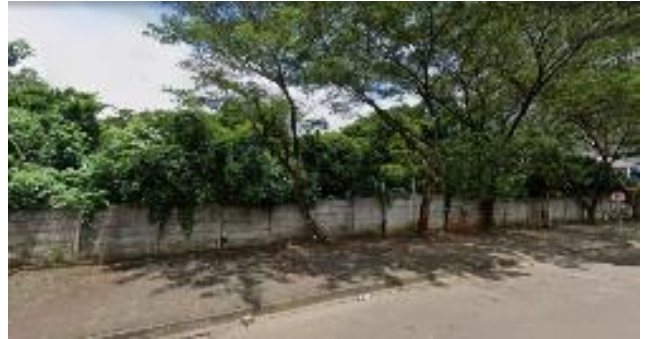

Gambar 4. Kondisi bagian depan tapak (Jl. Edutown)

sumber: googlemaps.com diakses 2 Juli 2021

Melihat dari kondisi tapak yang berada di tengah kawasan hunian di kecamatan Pagedangan yang memiliki penduduk dengan usia sekolah mencapai 4.247 jiwa (Tangerang, 2020), berada di pusat pendidikan terpadu kawasan BSD City yaitu Edutown, dan memiliki banyak fasilitas pendukung seperti universitas, dekat dengan stasiun intermoda Cisauk, rumah sakit serta asrama yang dapat menunjang keberadaan proyek "Ekstrakurikuler Pendidikan Ekologi" ini . Kondisi eksisting tapak berupa tanah kosong yang ditumbuhi vegetasi liar. Vegetasi dan landscape dipertahankan dan ditata kembali sesuai kebutuhan narasi untuk kelas terbuka, perkebunan dan miniatur hutan, dan program lainnya sebagai pendidikan lingkungan. Diharapkan wadah dan program baru untuk warga ini dapat meningkatkan kepedulian terhadap lingkungan, sehingga kesejahteraan warga serta lingkungan sekitar meningkat.

\section{DISKUSI DAN HASIL}

Pengalaman dan pemahaman spasial ruang serta makna yang dirasakan oleh setiap orang saat berkunjung pasti berbeda-beda. Tetapi dengan adanya kerangka narasi/alur dapat mempengaruhi zoning ruang dan sirkulasi yang ada sehingga setiap individu dapat memahami serta merasakan maksud yang sama dengan kerangka yang dibuat oleh arsitek, sehingga dapat tercipta generasi penerus bangsa yang peduli akan pentingnya alam dan lingkungannya. Usaha ini merupakan tindakan preventif akan kerusakan alam dan lingkungan di masa sekarang dan mendatang. 


\section{Empat Tahapan Narasi Ekologi}

Pembelajaran Tahap Pertama

Dalam pembelajaran tahap pertama, anak-anak diberi pengenalan dan diajarkan tentang dasar-dasar ekologi, fenomena-fenomena alam yang ada, bagaimana ekosistem bekerja.

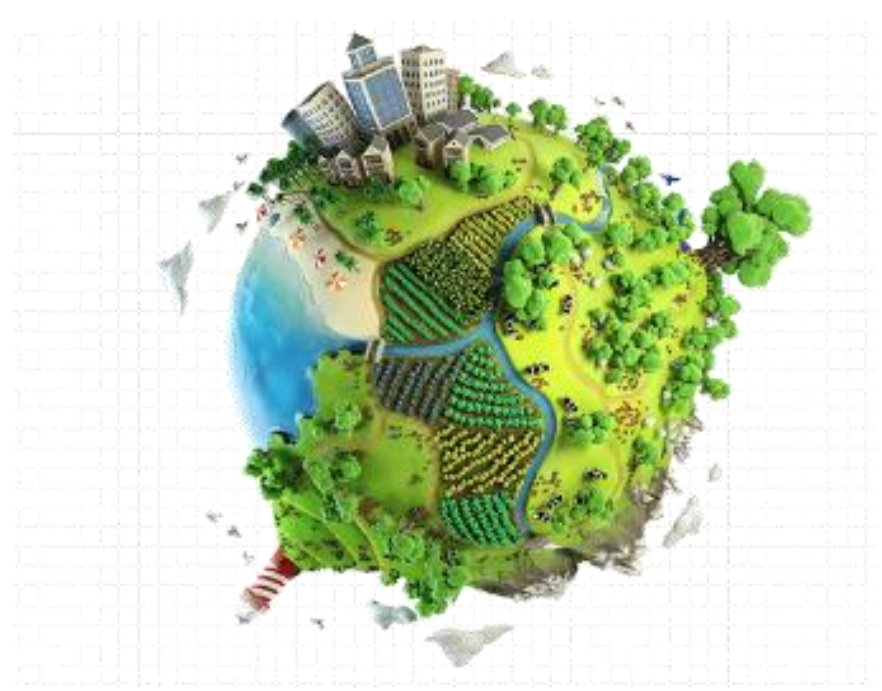

Gambar 5. Ilustrasi Ekosistem

Sumber: https://imgbin.com/png/2k18trdS/earth-png diakses 2 Juli 2021

\section{Pembelajaran Tahap Kedua}

Dalam pembelajaran tahap kedua, anak-anak diberi pengalaman tentang kerusakan ekologi seperti mencairnya es, penebangan hutan, peningkatan suhu dan dampaknya terhadap kehidupan

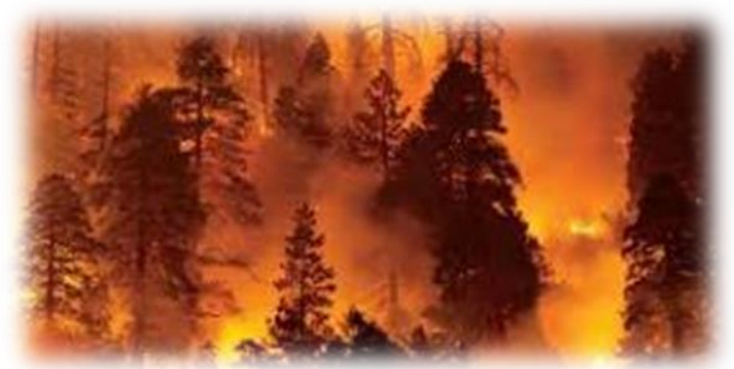

Gambar 6. Ilustrasi Kebakaran Hutan Sumber: David McNew/Getty Images diakses 2 Juli 2021

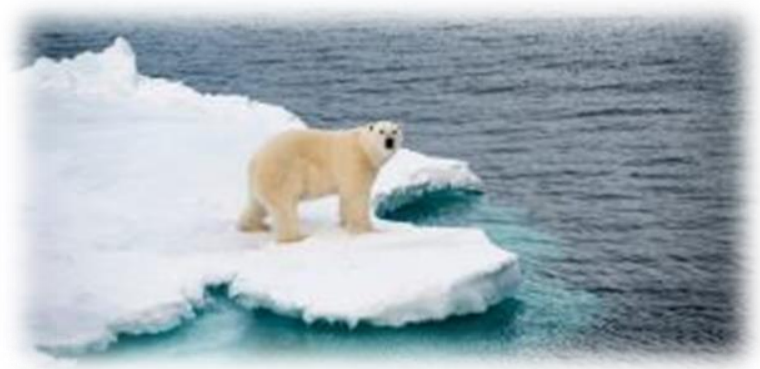

Gambar 7. Ilustrasi Es Kutub Mencair Sumber:

https://climatechange.ucdavis.edu/climatechange-definitions/arctic-sea-ice/ diakses 2 Juli 2021

\section{Pembelajaran Tahap Ketiga}

Dalam pembelajaran tahap ketiga, anak-anak diajarkan untuk memperbaiki ekologi dengan menanam pohon, cara hidup yang berkelanjutan dengan energi-energi terbarukan melalui eksperimen dan demonstrasi. 


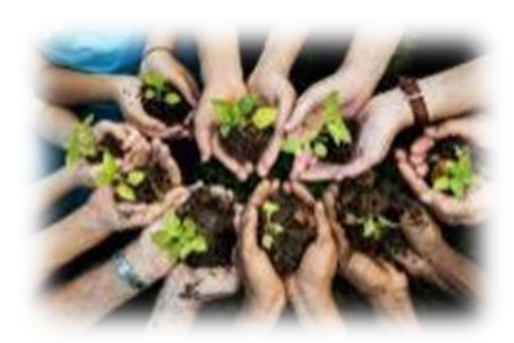

Gambar 8. Ilustrasi Menanam Pohon

Sumber: https://tafttribune.org/4622/culture/planting-trees/ diakses 2 Juli 2021

\section{Pembelajaran Tahap Keempat}

Dalam pembelajaran tahap keempat, anak-anak diajarkan untuk memelihara lingkungan, manfaatmanfaat dari pohon. Kehidupan dan biodiversitas yang terjadi di antara pepohonan.

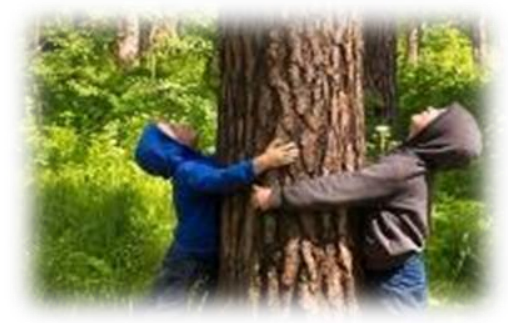

Gambar 9. Ilustrasi Memelihara Lingkungan

Sumber: https://www.shutterstock.com/search/kids+hugging+tree diakses 2 Juli 2021

Peletakkan komposisi massa menggunakan metode narasi, kondisi vegetasi eksisting tapak dan menggunakan teori elemen kota Kevin Lynch.

\section{Kondisi Vegetasi Eksisting}

Kondisi vegetasi eksisting cukup rimbun namun terpotong pada bagian tengah yang gersang. Kondisi alami ini dimanfaatkan dan diintegrasikan dengan narasi ekologi dimana bagian depan yang rimbun digunakan untuk pembelajaran tahap satu yaitu awal mula ekologi, sedangkan pada bagian tengah yang gersang untuk pembelajaran tahap dua dan tiga yaitu kerusakan ekologi dan perbaikan ekologi, lalu pada bagian rimbun yang terakhir untuk pembelajaran tahap empat yaitu keberlangsungan ekologi. Kondisi vegetasi dibiarkan se-alami mungkin sehingga Peletakkan dan bentuk massa menyesuaikan pola vegetasi yang ada (lihat gambar 12 ).

Integrasi narasi ekologi, kondisi vegetasi eksisting dengan elemen pembentuk kota "The Image of The City "Kevin Lynch:

\section{a. Path}

Terdapat segregasi antara sirkulasi kendaraan dengan manusia di path ini, serta adanya sirkulasi primer yang mengikuti alur narasi serta jalur sekunder untuk jalan pintas (lihat gambar 10 dan 12).

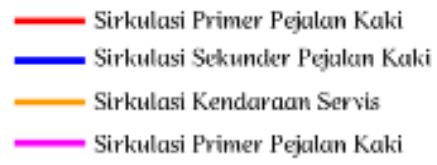

Gambar 10. Notasi Path pada Diagram Proses Zoning dan Peletakkan Massa Sumber: Penulis, 2021

\section{b. Edges - - -}

Edges pada tapak ini yaitu berupa dinding perimeter sebagai batasnya, namun batas tersebut diperhalus dengan kehadiran pohon dan semak-semak (lihat gambar 12). 


\section{c. District}

District pada kawasan ini dibagi berdasarkan pada tahapan narasi ekologi yang memanfaatkan kondisi eksisting vegetasi pada tapak (lihat gambar 11 dan 12).

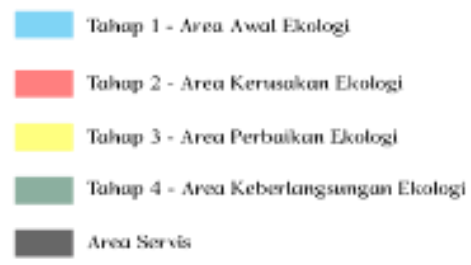

Gambar 11. Notasi District pada Diagram Proses Zoning dan Peletakkan Massa Sumber: Penulis, 2021

\section{d. Nodes}

Nodes terbentuk dari persimpangan antar path, serta ruang-ruang singgah seperti drop off, rumah pohon, dan ruang terbuka untuk camping (lihat gambar 12).

\section{e. Landmark}

Landmark pada tapak ini terletak pada area kerusakan ekologi yang berada di tengah tapak yang berwujud gunung es mencair yang menjadi pusat perhatian dan titik temu di kawasan ini (lihat gambar 12).

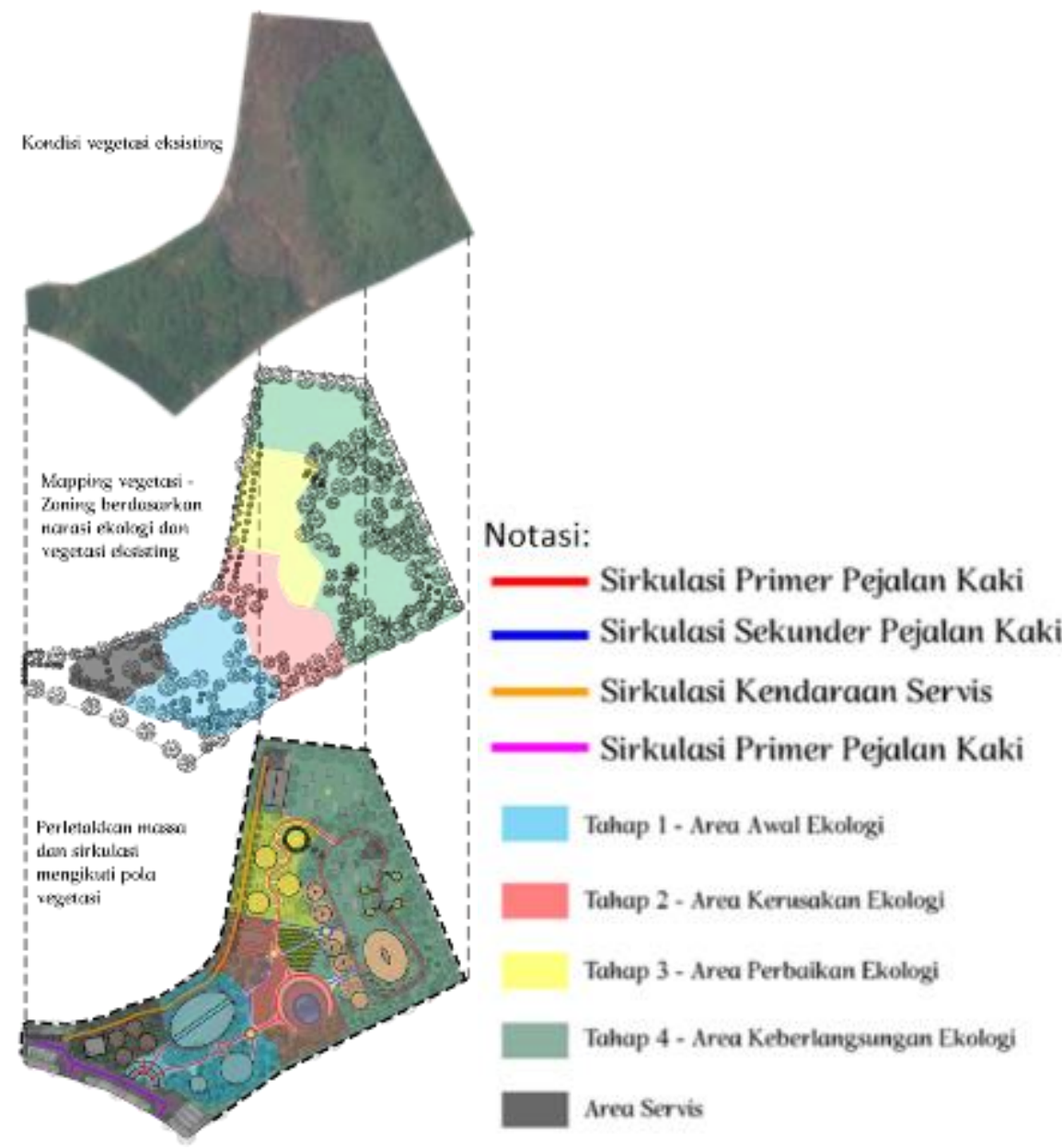

Gambar 12. Diagram Proses Zoning dan Peletakkan Massa Sumber: Penulis, 2021 
Massa di dominasi oleh bentuk lingkaran dan material bambu dengan tujuan untuk berbaur dengan kedinamisan vegetasi pepohonan yang ada (lihat gambar 13).

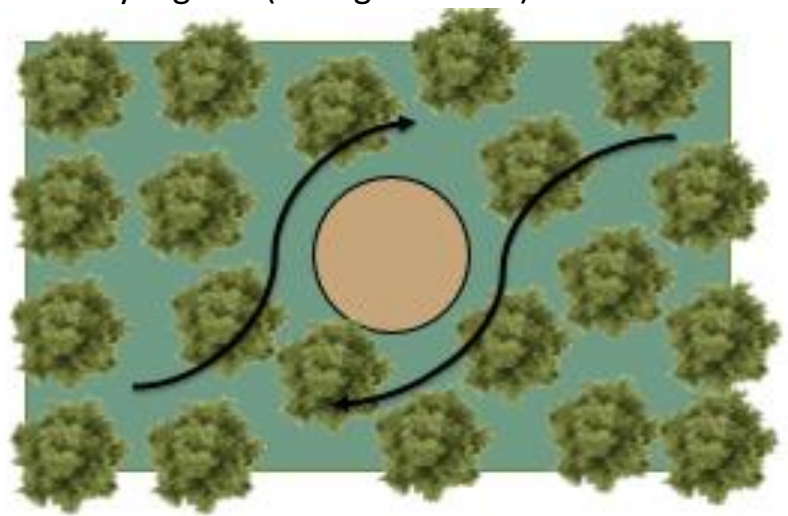

Gambar 13. Diagram Bentuk Massa Terhadap Vegetasi Sumber: Penulis, 2021

\section{Pembelajaran Tahap 1-Awal Mula Ekologi}

Dalam pembelajaran tahap pertama, anak-anak diberi pengenalan dan diajarkan tentang dasar-dasar ekologi, fenomena-fenomena alam yang ada, bagaimana ekosistem bekerja. Kelas disini menggunakan kelas terbuka, tanpa dinding dan jendela yang bertujuan agar anak-anak lebih banyak mendapatkan asupan udara segar, dan terjadinya kesinambungan pembelajaran dengan lingkungan dengan persentase ruang luar dan dalam yaitu sebesar $70 \%$ untuk ruang luar dan $30 \%$ untuk ruang dalam.

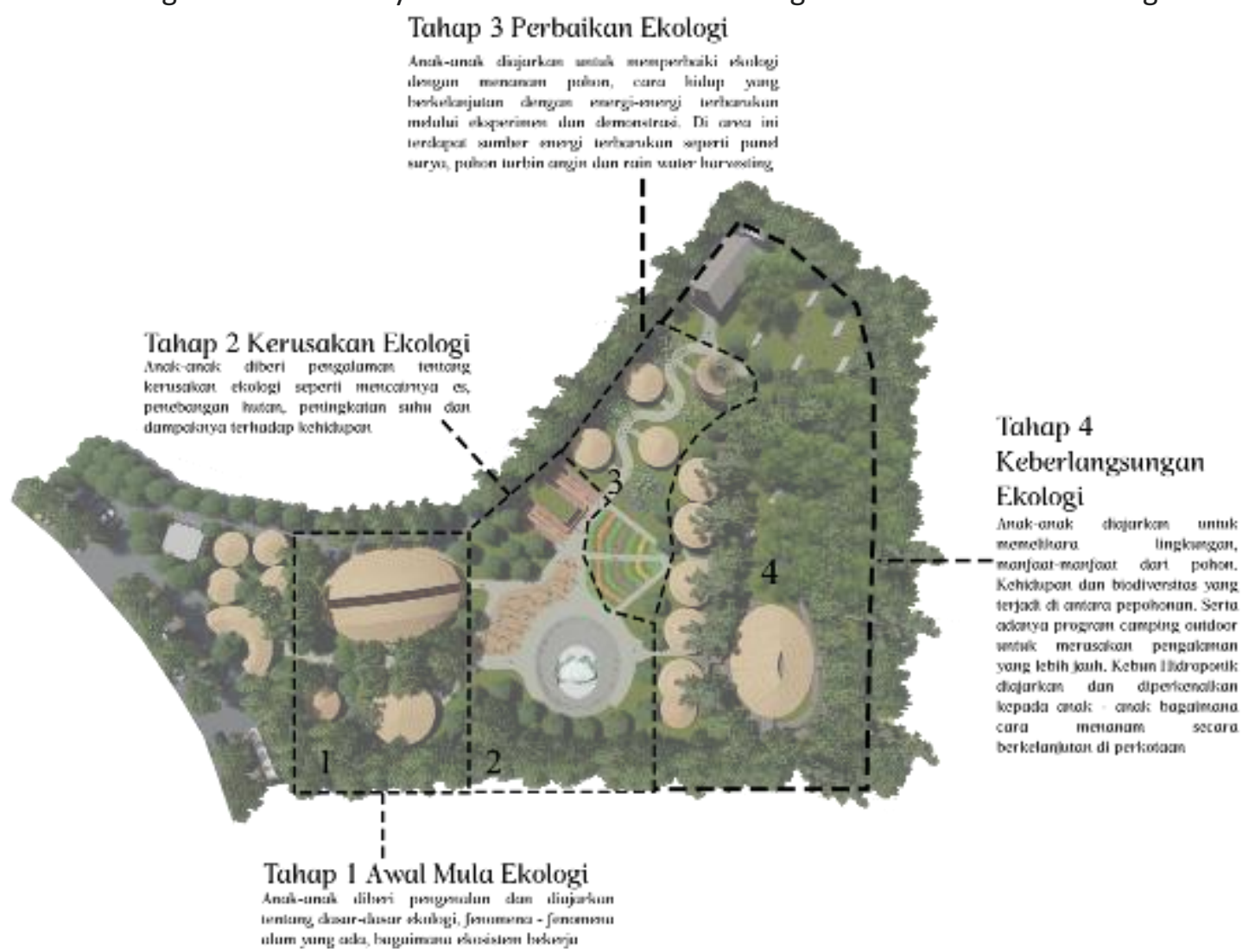

Gambar 14. Diagram Pembagian Area Tahapan Pembelajaran Narasi Ekologi

Sumber: Penulis, 2021

\section{Area Drop Off}

Area drop off ini merupakan gerbang dari semua rangkaian perjalanan ekologi anak-anak di dalam tapak. Adanya pohon di tengah area drop off sebagai perlambangan titik awal dan kehidupan. 
Bentukkan massa setengah lingkaran ini dimaksudkan untuk memberikan 'sambutan' yang merangkul untuk masuk ke dalamnya.
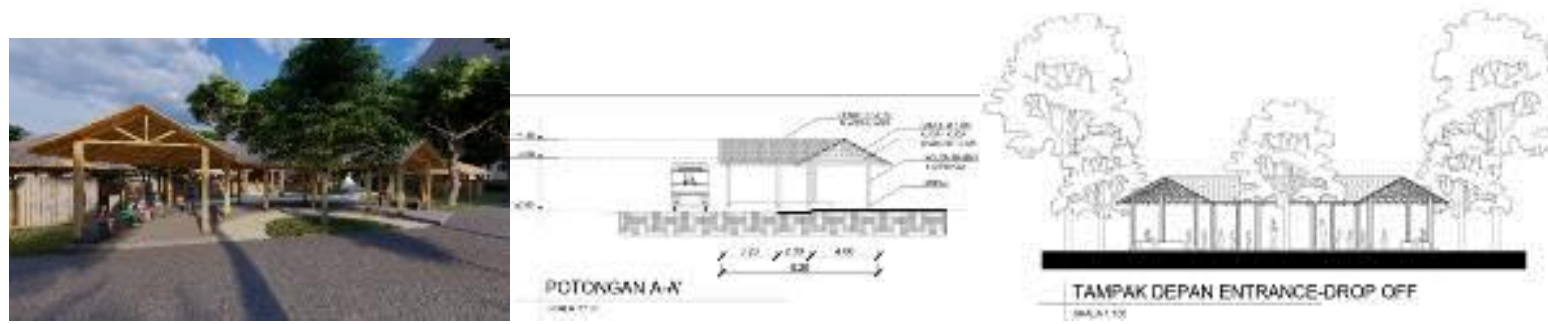

Gambar 15. Perspektif, Potongan, dan Tampak Area Drop Off Sumber: Penulis, 2021

\section{Ruang Ruang Serbaguna}

Ruang serbaguna ini berfungsi sebagai tempat singgah pertama anak-anak, tempat untuk memberikan pengarahan awal tentang prosesi pembelajaran selama di dalam tapak dan sebagai tempat untuk berbagai macam acara dan kegiatan.

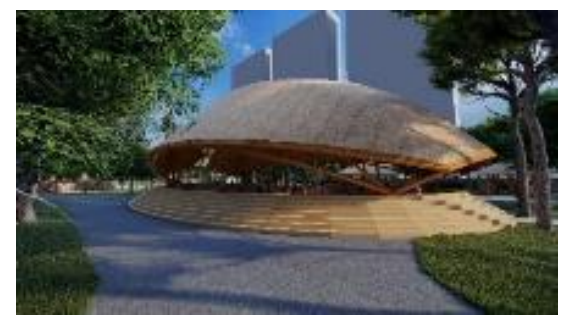

Gambar 16. Ruang Serbaguna Sumber: Penulis, 2021

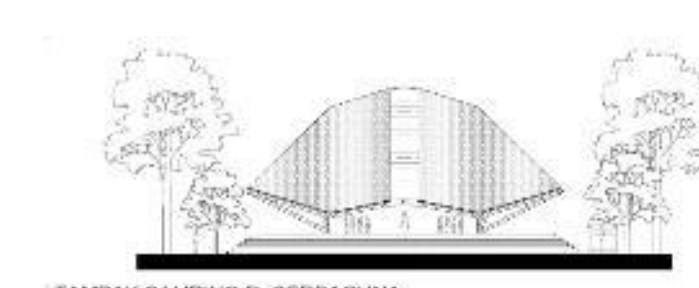

TAMPAK SAMPINGR. SERBACUNA

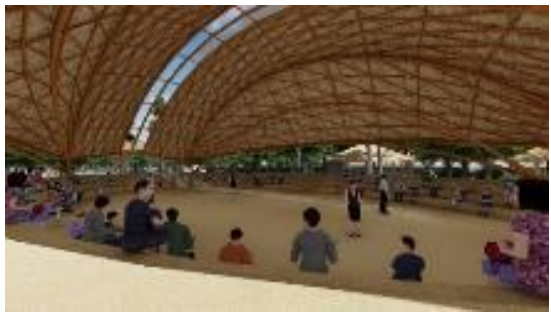

Gambar 17. Interior Ruang Serbaguna Sumber: Penulis, 2021

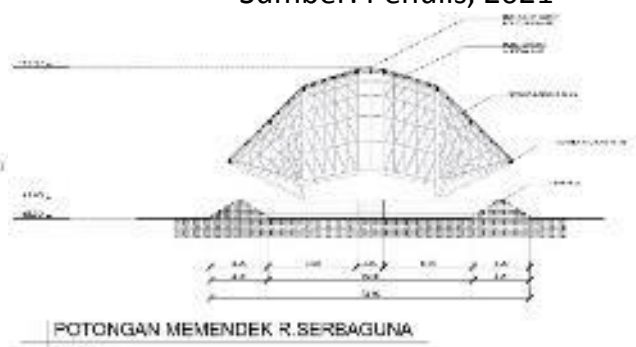

Gambar 18. Tampak dan Potongan R.Serbaguna Sumber: Penulis, 2021

\section{Ruang Audiovisual}

Berfungsi sebagai tempat interaktif anak untuk memahami fenomena-fenomena alam, dan dasar dasar ekologi.
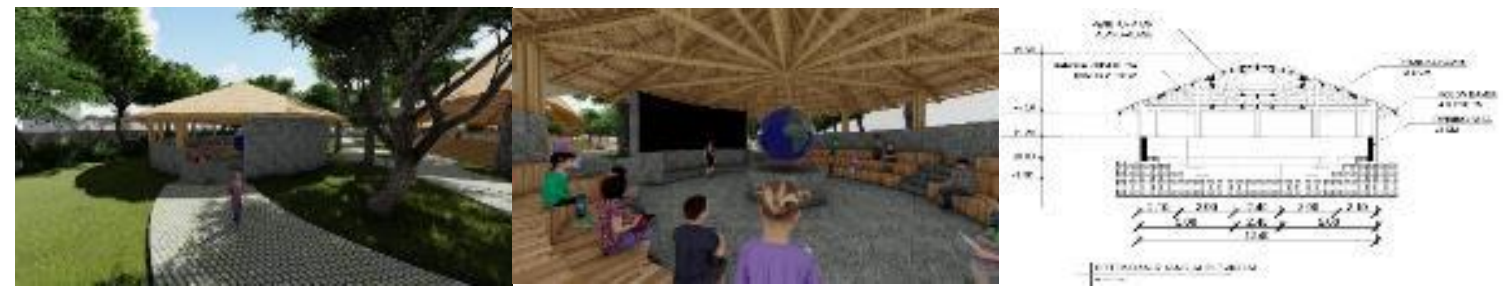

Gambar 19. Perspektif dan Potongan Ruang Audiovisual Sumber: Penulis, 2021 


\section{Ecoshop}

Ecoshop ini merupakan toko yang memperjualbelikan hasil-hasil kebun dan hidroponik di dalam tapak
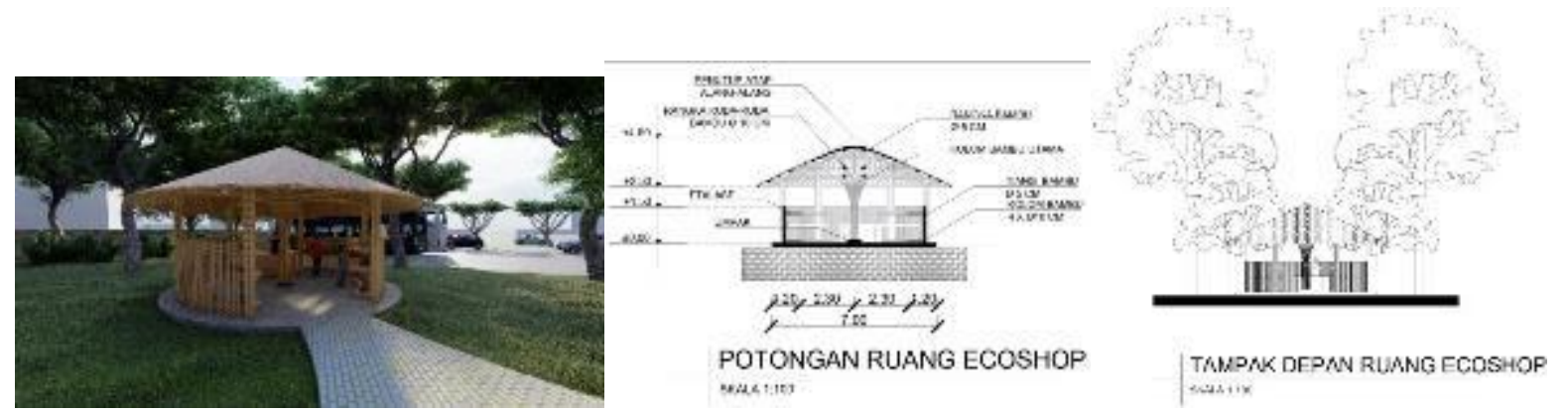

Gambar 20. Perspektif, Potongan dan Tampak Ruang Ecoshop

Sumber: Penulis, 2021

\section{Pembelajaran Tahap 2-Kerusakan Ekologi}

Dalam pembelajaran tahap kedua, anak-anak diberi pengalaman tentang kerusakan ekologi seperti mencairnya es, penebangan hutan, peningkatan suhu dan dampaknya terhadap kehidupan. Pada tahap ini pemebelajaran menggunakan pengalaman ruang, sehingga anak-anak dapat lebih merasakan dan lebih menghargai alam kedepannya.

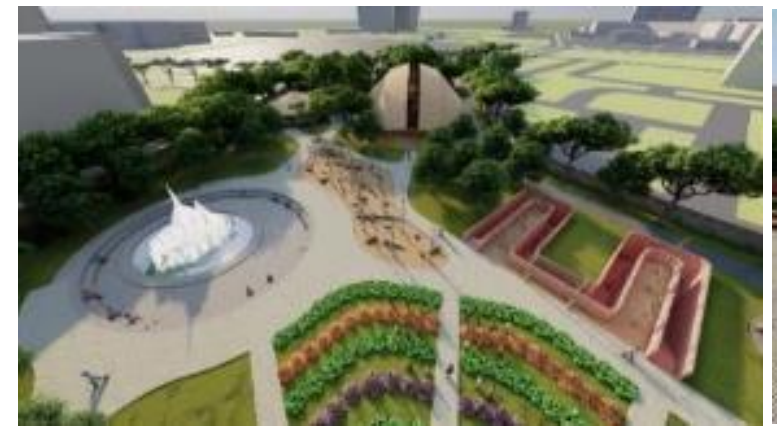

Gambar 21. Area Kerusakan Ekologi Sumber: Penulis, 2021

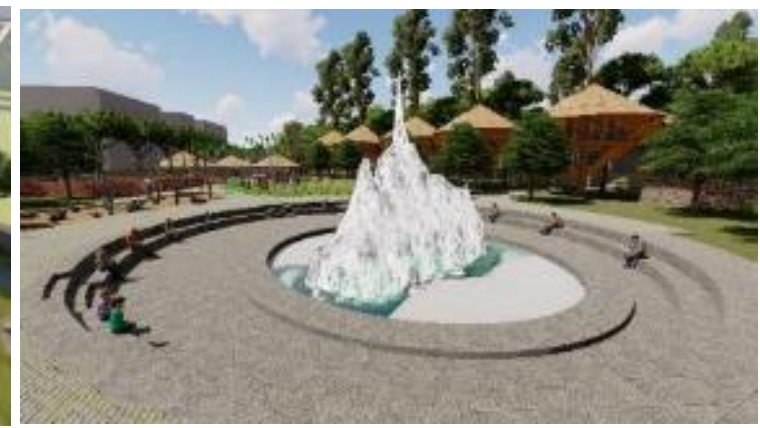

Gambar 22. Diorama Es Mencair Sumber: Penulis, 2021

\section{Diorama Es Mencair}

Pada area ini anak-anak diberi pemahaman tentang bagaimana dampak yang diakibatkan oleh pemanasan global sehingga suhu bumi naik dan es di kutub mencair.

\section{Diorama Deforestasi}

Pada area ini anak-anak diberi pemahaman tentang bagaimana dampak yang diakibatkan oleh penebangan hutan sehingga menyebabkan pemanasan global dan hilangnya habitat satwa liar

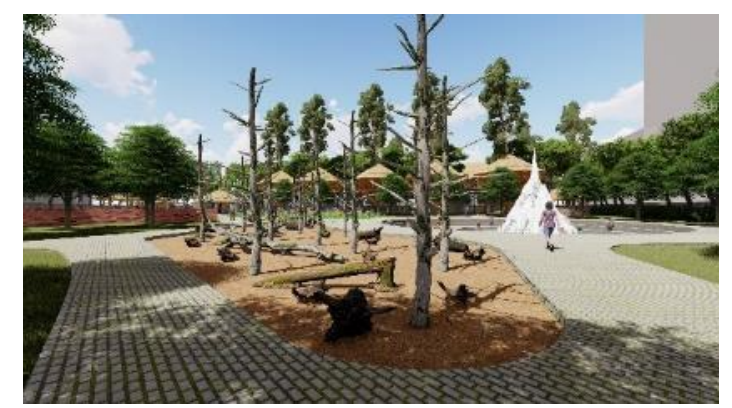

Gambar 23. Diorama Deforestasi

Sumber: Penulis, 2021 


\section{Labirin Hotzone}

Pada area ini anak-anak merasakan pengalaman ruang yang pengap dan panas yang merepresentasikan pemanasan global.

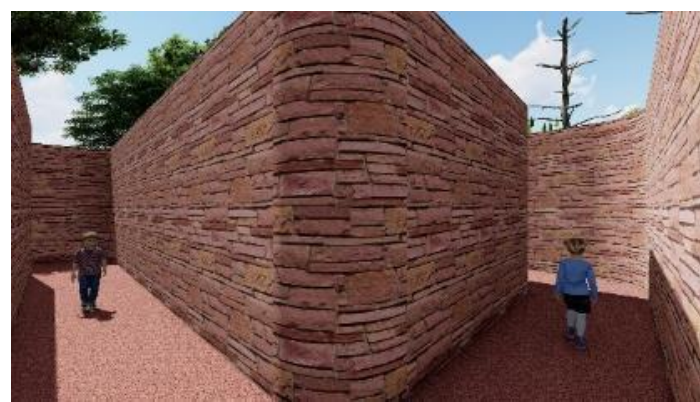

Gambar 24. Labirin Hotzone

Sumber: Penulis, 2021

\section{Pembelajaran Tahap Ketiga-Perbaikan Ekologi}

Anak-anak diajarkan untuk memperbaiki ekologi dengan menanam pohon, cara hidup yang berkelanjutan dengan energi-energi terbarukan melalui eksperimen dan demonstrasi. Di area ini terdapat sumber energi terbarukan seperti panel surya, pohon turbin angin dan rain water harvesting yang juga merupakan akses menuju canopy walk

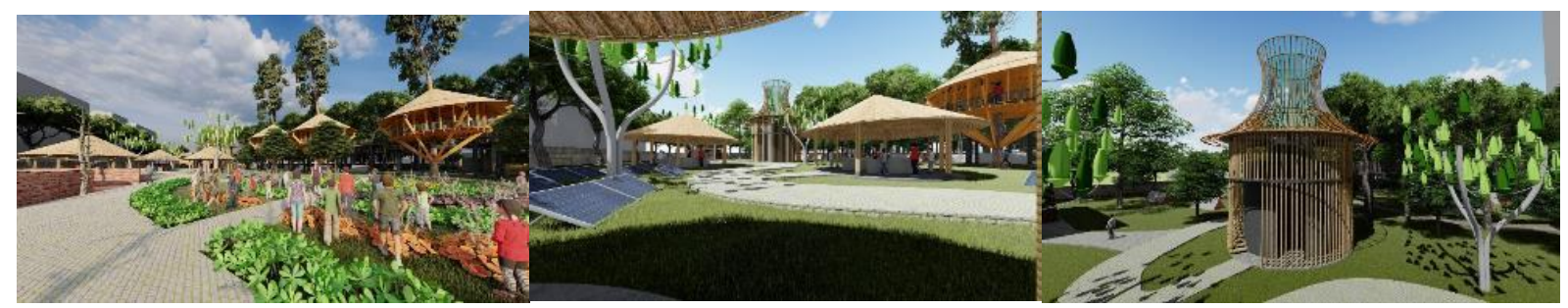

Gambar 25. Area Perbaikan Ekologi

Sumber: Penulis, 2021

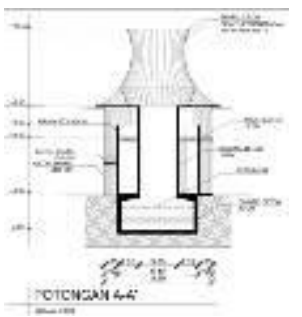

Gambar 26. Potongan \& Tampak Rain Water Harvesting

Sumber: Penulis, 2021

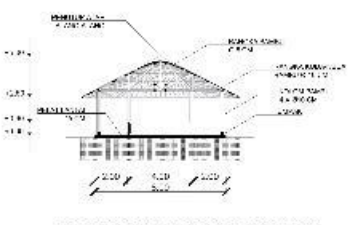

POTONGAN RUANG WORKSHOP

Gambar 27. Potongan \& Tampak Workshop Sumber: Penulis, 2021

\section{Pembelajaran Tahap Keempat-Keberlangsungan Ekologi}

Pada area ini anak-anak diajarkan untuk memelihara lingkungan, manfaat-manfaat dari pohon. Kehidupan dan biodiversitas yang terjadi di antara pepohonan. Serta adanya program camping outdoor untuk merasakan pengalaman yang lebih jauh. Kebun hidroponik diajarkan dan diperkenalkan kepada anak-anak bagaimana cara menanam secara berkelanjutan di perkotaan. 


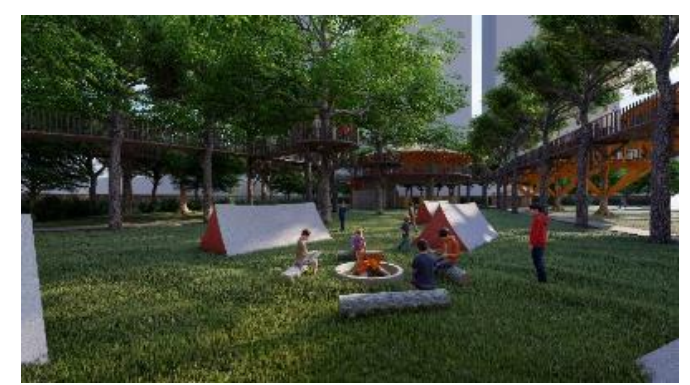

Gambar 28. Area Keberlangsungan Ekologi-Area Camping Sumber: Penulis, 2021

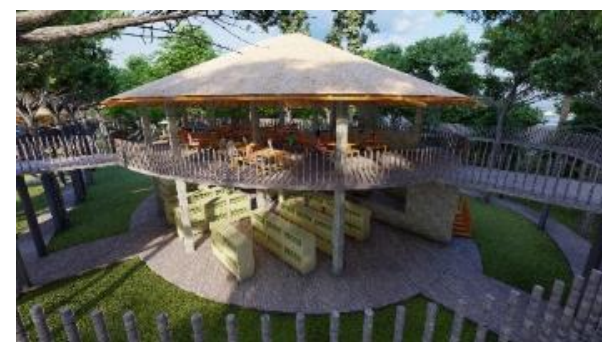

Gambar 29. Area Makan dan Hidroponik Sumber: Penulis, 2021

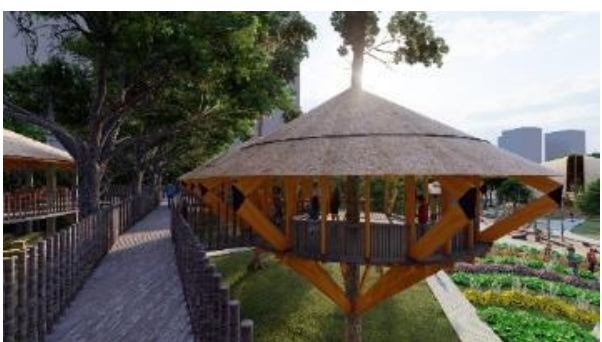

Gambar 30. Kelas Rumah Pohon Sumber: Penulis, 2021

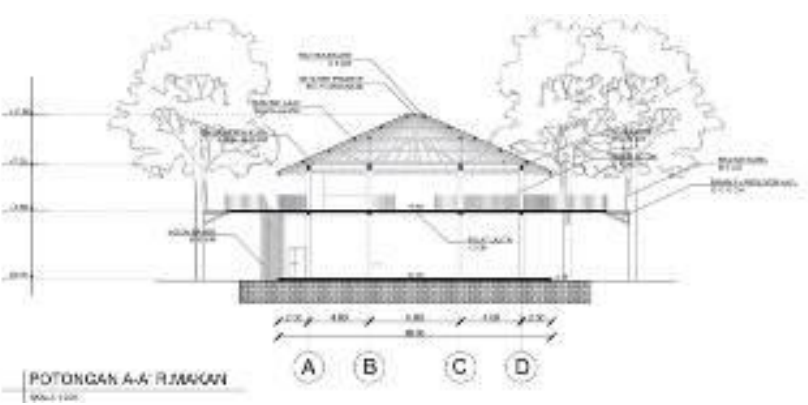

Gambar 31. Area Makan dan Hidroponik Sumber: Penulis, 2021

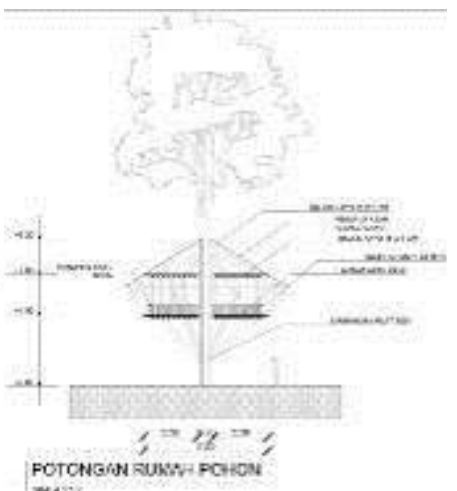

Gambar 32. Area Makan dan Hidroponik Sumber: Penulis, 2021

\subsection{Canopy Walk-Resting Net}

Pada area ini anak-anak berjalan di antara pepohonan, melihat biodiversitas dan kehidupan yang terjadi di pepohonan, serta ada area singgah outdoor berupa jaring untuk anak-anak bermain dan istirahat.

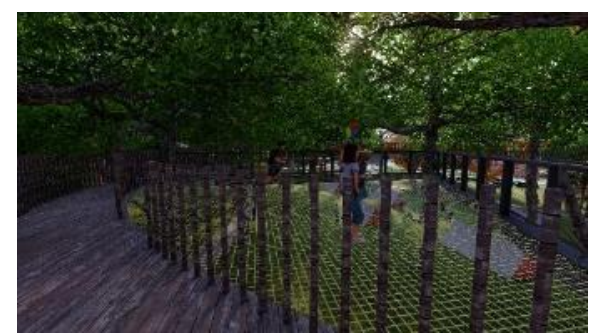

Gambar 33. Canopy Walk-Resting Net

Sumber: Penulis, 2021 


\section{KESIMPULAN DAN SARAN \\ Kesimpulan}

Pada proyek Pendidikan Ekstrakurikuler Pendidikan Ekologi di Kawasan Edutown BSD ini bertujuan untuk membentuk konsepsi dan mendorong anak-anak untuk sadar akan lingkungan. Dengan menggunakan metode narasi dalam peletakkan dan menciptakan ruang serta pembelajaran diharapkan anak-anak dapat berkontemplasi dan merasakan pentingnya menjaga lingkungan melalui program ini. Perletakkan fungsi serta massa yang linear serta progresif dari arah depan menuju belakang bertujuan untuk menciptakan pola pikir yang runut dari pemahaman awal konsepsi tentang ekologi, lalu menuju aktifitas pembelajaran dan eksperimen. Melalui proyek ini kesadaran, pola pikir dan perilaku siswa-siswa terhadap alam dan lingkunganya dapat berubah, sehingga tercipta generasi penerus bangsa yang tidak hanya cerdas secara intelektual, namun juga akhlak kepada Tuhan, sesama dan lingkungan. Sehingga kedepannya manusia dapat berjalan berdampingan dengan alam dan menjaga keberlangsungannya.

\section{Saran}

Diharapkan proyek serupa dapat diterapkan dan dikembangkan di tempat-tempat lainnya, sehingga dapat menularkan dampak positif dan rasa peduli terhadap lingkungan, sebagai usaha kolektif dalam memerangi kerusakan lingkungan.

\section{REFERENSI}

Bella, A. (2020, Oktober 8). Ekologi Adalah. Dipetik Februari 19, 2021, dari Dosen.co.id: https://pakdosen.co.id/ekologi-adalah/

Dosen Pendidikan 2. (2020, Desember 20). Ekologi - Pengertian Menurut Para Ahli, Materi, Ruang Lingkup Dan Perbedaan. Dipetik Februari 19, 2021, dari Dosen Pendidikan: https://www.dosenpendidikan.co.id/ekologi/

Kuh, L., Ponte, I., \& Chau, C. (2013). The Impact of a Natural Playscape Installation on Young Children's Play Behaviour. Children, Youth and Environments, 23(2), 49-77. doi:https://doi.org/10.7721/chilyoutenvi.23.2.0049

Luken, E., Carr, V., \& Brown, R. D. (2014). Playscape: Designs for Play, Exploration and Science Inquiry. Children, Youth and Environments, 21(2), 325-337. doi:10.7721/chilyoutenvi.21.2.0325

Lynch, K. (1960). The Image of the City. Cambridge: The M.I.T. Press.

Orr, D. W. (1992). Ecological Literacy: Education and the Transition to a Postmodern World. Albany: State University of New York Press.

Psarra, S. (2009). Architecture and Narrative: The Formation of Space and Cultural Meaning. London and New York: Routledge.

Suhendi, S., \& Murdiana, S. (2011). Belajar Bersama Alam. Bogor: SoU Publisher.

Susilo, R. D. (2008). Sosiologi Lingkungan. Jakarta: Raja Grafindo Perkasa.

Sutanto, A. (2020). Peta Metode Desain. Jakarta: eBook.

Tangerang, B. P. (2020). Kecamatan Pagedangan Dalam Angka 2019. Tangerang: Badan Pusat Statistik Kabupaten Tangerang.

Tissink, F. E. (2016). Narrative Driven Design: Roles of Narratives for Designing the Built Environment. Delft: TU Delft.

Zepke, N., \& Leach, L. (2010). Improving Student Engagement: Ten proposals for action. Active Learning in Higher Education, 11(3), 167-177. doi:10.1177/1469787410379680 
